\title{
Intrinsic Differences on the Photodegradation Mechanisms between Pigmented and Non-Pigmented Coatings Determined by Multi-Scale Analysis
}

\author{
Takato Ishida $^{1}$, Ryoma Kitagaki ${ }^{2}$, Hideaki Hagihara ${ }^{3}$ and Yogarajah Elakneswaran ${ }^{4}$ \\ ${ }^{1}$ Ph.D. student, Graduate School of Engineering, Hokkaido University, Nishi-8-chome, Kita-13-jyo, \\ Kita-ku, Sapporo-shi, Hokkaido, 060-8628, Japan, takato.matphysichem@gmail.com \\ ${ }^{2}$ Graduate School of Engineering, Hokkaido University, Nishi-8-chome, Kita-13-jyo, Kita-ku, \\ Sapporo-shi, Hokkaido, 060-8628, Japan, ryoma@eng.hokudai.ac.jp \\ ${ }^{3}$ Research Institute for Sustainable Chemistry, National Institute of Advanced Industrial Science and \\ Technology (AIST), Tsukuba, Ibaraki, 305-8565, Japan, h-hagihara@aist.go.jp \\ ${ }^{4}$ Graduate School of Engineering, Hokkaido University, Nishi-8-chome, Kita-13-jyo, Kita-ku, \\ Sapporo-shi, Hokkaido, 060-8628, Japan, elakneswaran@eng.hokudai.ac.jp
}

\begin{abstract}
Multi-scale analysis of photodegradation are conducted for pigmented coating containing acrylic urethane $+\mathrm{TiO}_{2}$ pigment and for non-pigmented coating containing only acrylic urethane. We discuss the intrinsic differences in the photodegradation mechanism between the pigmented and nonpigmented coatings and the effect of the interface between the pigment and the binder. Photo-aging tests are conducted using artificial ultraviolet (UV) irradiation under conditions of $60^{\circ} \mathrm{C}$ and dry atmosphere. The results of Fourier transform infrared spectroscopy (FTIR), solvent swelling experiments, ultrasonic measurements of elastic moduli, and colourimetry used for material characterisation before and after photo-aging. Although the behaviour of $E$ and the carbonyl index (CI) show common trends for both samples, the overall trends of yellowness index (YI) and swelling degree (Q) differ significantly between the pigmented and non-pigmented samples. The results reveal that changes in macroscopic properties may not necessarily correspond with the CI behaviour and that characteristic interfacial effects exist between the pigment and the binder. The onsets of coating erosion and chalking are observed in the pigmented coating as surface topological changes. The different behaviour of YI and $Q$ between the sample types can be attributed to the interfacial effect at pigment/binder interface based on the photocatalytic effect from $\mathrm{TiO}_{2}$ pigment.
\end{abstract}

Keywords: Photodegradation, Coatings, Internal Morphology, Photo-Aging, Multi-Scale Analysis.

\section{Introduction}

The durability of protective surface coatings is a critical factor for long-term quality with respect to buildings and infrastructures because these coatings act as gas barrier material and enhance the aesthetic qualities. Thus, improvement is needed in the long-term performance of these coatings, and an appropriate evaluation procedure should be established.

For assessing the degree of degradation in polymer-based materials, the carbonyl index $(\mathrm{CI})$ is commonly applied because it reflects the macroscopic degradation occurring in barrier properties, elasticity, and surface colour and gloss in these materials. Although it is well accepted as a relevant criterion, CI may be not appropriate for evaluating the degradation level in all physical properties (Rouillon et al., 2016). CI could be applied to analyse the chemical oxidation level microscopically; however, it is not appropriate for evaluating some macroscopic 
properties related to the material's internal morphology such as macromolecular architecture, pore structure, and configuration of fillers. Hence, recent multi-scale degradation research has been conducted to analyse microscale phenomena and macroscale properties with a focus on mesoscale alteration of materials (Courvoisier et al., 2018; Richaud et al., 2010).

Two types of coatings are used for buildings and construction: pigmented and nonpigmented in coloured and clear coatings, respectively. Unfortunately, it can be difficult to evaluate the degradation level by applying only a single index to the durability of both coating types because they exhibit intrinsic differences in the photodegradation mechanisms such as the interfacial effect between the pigment and the binder, as evidenced by the differences in internal structures.

In this work, multi-scale analysis of photodegradation is conducted for both pigmented and non-pigmented coatings, as shown in Figure 1. We analyse the intrinsic differences noted in photodegradation between the two coatings and the effect of the interface between the pigment and the binder. Titanium dioxide $\left(\mathrm{TiO}_{2}\right)$ is most commonly used as white pigment for coatings of buildings owing to its good brightness and photo-catalytic effect. However, the photocatalytic effect might be responsible for these differences because it produces hydroxyl radicals $(\cdot \mathrm{OH})$ under ultraviolet (UV) irradiation as part of the decomposition of surface contaminants (Pang et al. 2014).
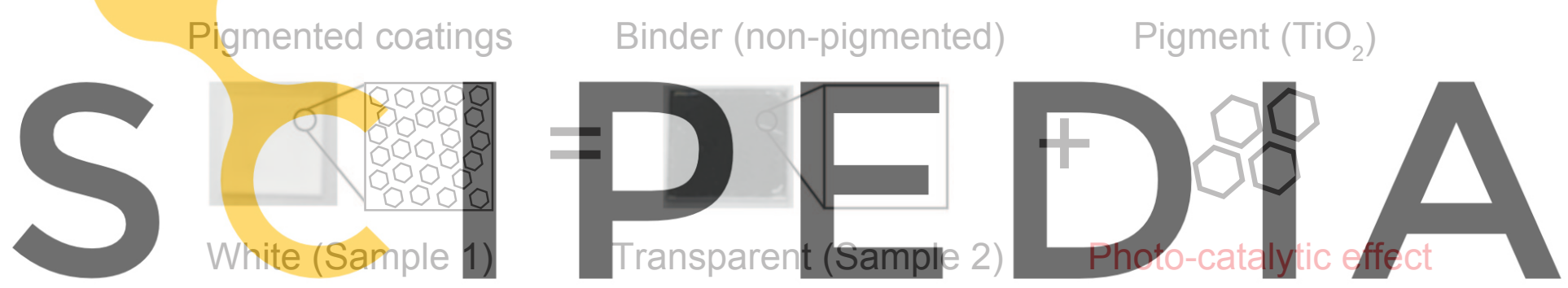

Figure 1. Composition of sample coatings

Register for free at https//www.scipedia.com to download the version without the watermark 2 Materials and Experimental Methods

\subsection{Coating Sample Preparation}

The coating was applied on Si substrates using the spin-coating technique at a speed of 2000 rpm for both the pigmented and non-pigmented coatings. The pigmented coating, which was purchased from Japanese industry, is a two-part-type urethane-based white paint (Sample 1). The main chemical component of the pigmented paint was analysed by pyrolysis gas chromatography mass spectroscopy, which detected acrylic polyol and hexamethylene diisocyanate (HDI) trimer. The elemental analysis revealed that the pigment particles are composed of $\mathrm{TiO}_{2}$. The non-pigmented paint (Sample 2) was provided by Japanese industry. This paint had the similar chemical structure as that detected in the binder component of Sample 1 - acrylic urethane - with no additives.

The curing process was the same as that discussed in our previous study (Ishida et al., 2019). The thickness of the coating film sample was approximately $30 \mathrm{um}$ and $10 \mathrm{um}$ for the pigmented and non-pigmented samples, respectively. The reason for using such thin film samples was to obtain homogeneously degraded samples with no obvious heterogeneous oxidation. 


\subsection{Artificial Photo-Aging}

Ultraviolet irradiation was performed by simulating the aging conditions by UV irradiation in our lab (Ishida et al., 2019). This apparatus effectively controls the sample surface temperature under UV irradiation by blown air to eliminate radiation heat emitted by a metal halide lamp. The lamp was set with wavelengths below $295 \mathrm{~nm}$ and was filtered by using borosilicate glass; the light intensity was set at $180 \mathrm{~W} / \mathrm{m}^{2}$ (calculated $\lambda=300-400 \mathrm{~nm}$ ). Photo-aging tests were conducted under a surface temperature of $60{ }^{\circ} \mathrm{C}$ and low relative humidity (RH) at $<10 \%$.

\subsection{Characterisation Methods}

We performed multi-scale analysis of photodegradation according to the combined results of Fourier transform infrared spectroscopy (FTIR), solvent swelling experiments, ultrasonic measurements of elastic moduli, and colourimetry. The FTIR and solvent swelling experiments were conducted to detect changes in the chemical structure and in the pore structure, respectively, by using the same method as that reported in an earlier study (Ishida et al., 2019). Ultrasonic measurements were conducted by using an ultrasonic device (38DL, Olympus, Japan, and the elastic moduli $(E)$ were calculated on the basis of the ultrasonic speed in the materials (Göbel et al. 2018) as

$$
E=2 \rho v_{T}^{2}+\frac{v_{L}^{2}-2 v_{T}^{2}}{v_{L}^{2}-v_{T}^{2}} \rho v_{T}^{2}
$$

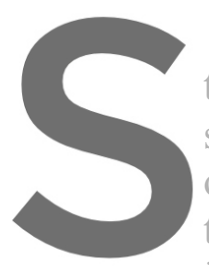

where $\rho$ is the sample the transverse wave sper spectrophotometer (CM observer set to $10^{\circ}$; the the yellowness index $(\mathrm{Y}$
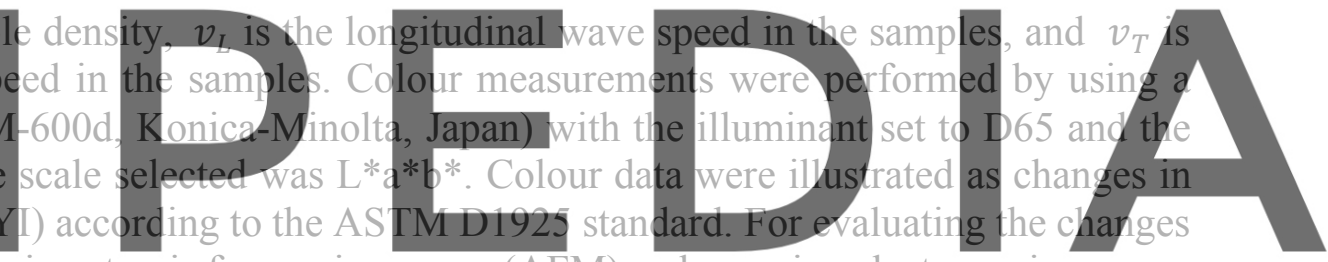

in surface topology, tapping atomic force microscopy (AFM) and scanning electron microscopy

Register for free at hatplied to the pigmented coatings.

\section{Results and Discussions}

Firstly, we evaluated the CI change behaviour in the aging process, which is a widely accepted degradation indicator. The $\mathrm{CI}$ is calculated as the ratio of the peak areas $(\mathrm{C}=\mathrm{O}$ vibration and $\mathrm{C}-$ $\mathrm{H}$ vibration) and is expressed as

$$
C I=\frac{A_{C=O}}{A_{C-H}}=\frac{\text { Peak area }\left(1600 \mathrm{~cm}^{-1}-1850 \mathrm{~cm}^{-1}\right)}{\text { Peak area }\left(2800 \mathrm{~cm}^{-1}-3000 \mathrm{~cm}^{-1}\right)}
$$

Figure 2 illustrates the $\mathrm{CI}$ behaviour for both pigmented and non-pigmented coating samples. Similar behaviours were shown, which indicates little difference in the chemical degradation (oxidation) rates between the two types. This result was expected because the chemical structures of their organic components are essentially the same. We then compared the CI and the macroscopic properties, E and YI. Figure 3 (a) illustrates the changes in E and YI values as a function of photo-aging time. For the pigmented sample, the E values roughly 


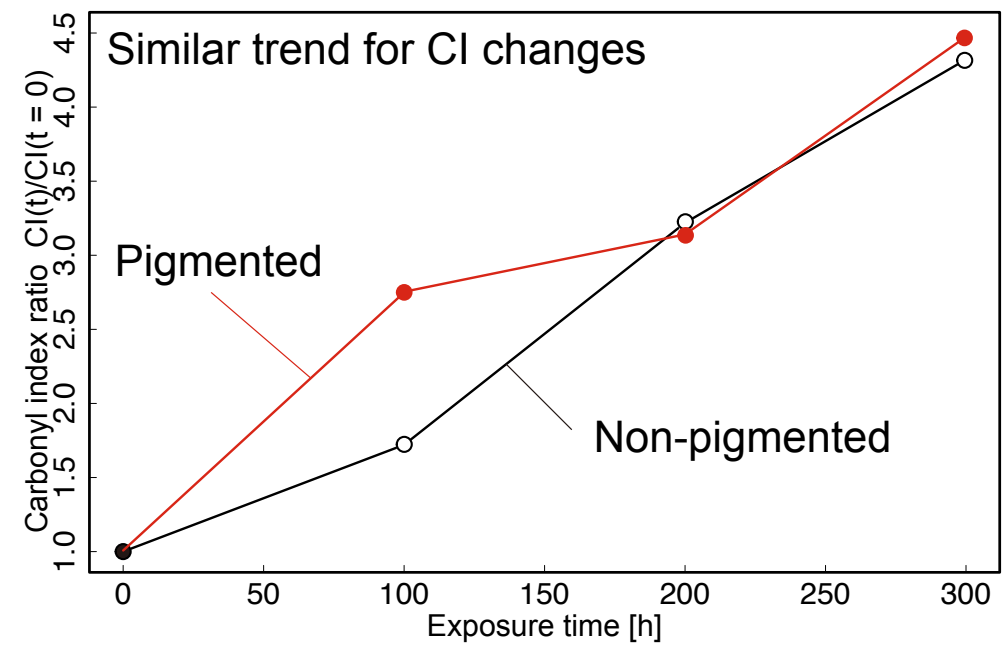

Figure 2. Carbonyl index (CI) as a function of exposure time for pigmented and non-pigmented coatings.
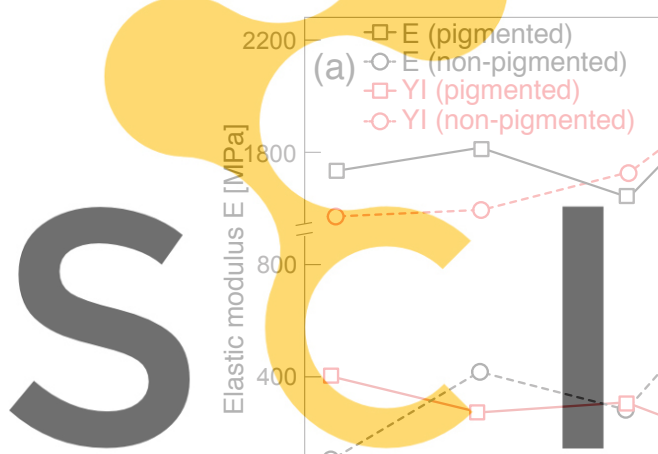

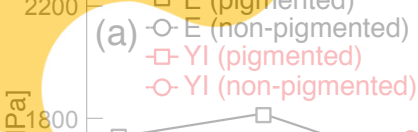
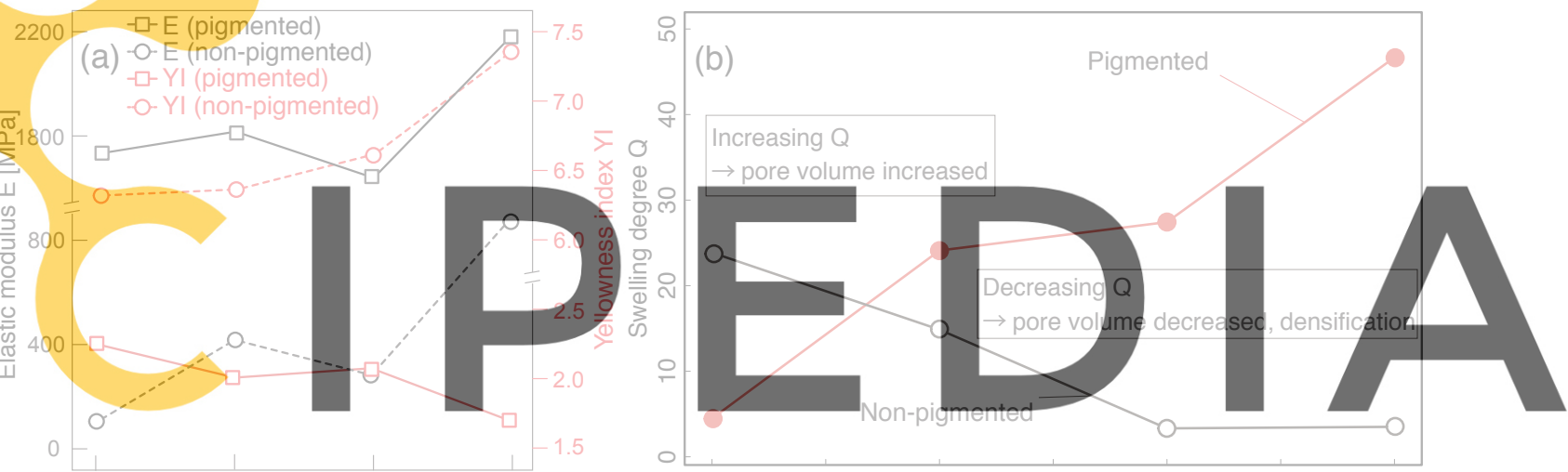

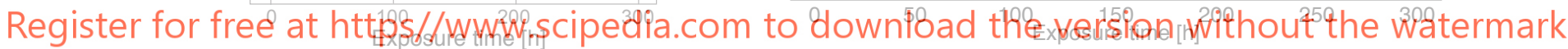

Figure 3. (a) Elastic modulus (E) and yellowness index (YI) as functions of exposure time for pigmented (solid lines) and non-pigmented coatings (dashed lines). (b) Swelling degree (Q) as a function of exposure time for pigmented and non-pigmented coatings.

increased and the YI values decreased with an increase in aging time. For the non-pigmented samples, the E value trend was similar to that in the pigmented samples; however, the YI values were decreased. Although the changes in E value behaviour corresponded with the CI behaviour for both coating types, those in the YI behaviour did not conform with the CI in the pigmented sample. In addition, a decrease in the $b^{*}$ value was observed in degraded pigmented samples, which implies a blue shift (Rosu et al., 2009). Although carbonyl species are well known as typical coloured chemical products, carbonyl growth may not necessarily contribute to yellowing in all pigmented coatings. Figure 4 illustrates the relationship of colour with the absorption wavelength and number of conjugated double bonds for coloured chemical products (Bacaloglu and Stewen, 2001). The results imply differences in the chain length of degraded (oxidised) chemical products between pigmented and non-pigmented coatings, i.e. yellow chemical products from non-pigmented samples had longer conjugated 


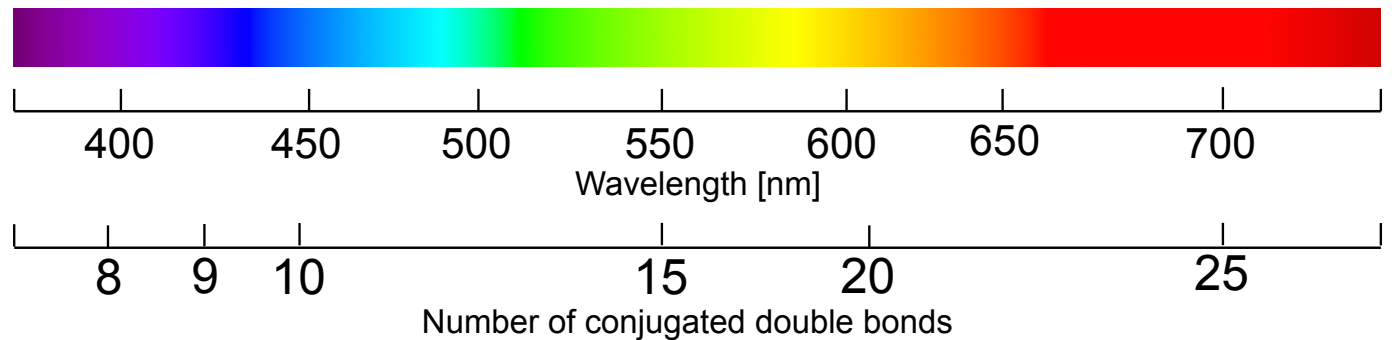

Figure 4. Continuous colour chart and its relationship with wavelength and number of conjugated double bonds.

double bonds than those from pigmented coatings. The photo-catalytic reaction of $\mathrm{TiO}_{2}$ on pigmented coatings may have increased the efficiency of chain scission compared with that in the non-pigmented coatings. In addition, this effect appears to have influenced even the internal morphological changes in photo-aging. The behaviour of swelling degree showed differences between both coating types, as shown in Figure 3 (b). The swelling degree is derived as the sample volume change ratio before and after immersion in a solvent, which in this case was toluene (Ishida et al., 2019), and may be related to the internal total pore volume. The pigmented samples might have become porous because the total pore volume increased for the pigmented coating; however, the pore volume for the non-pigmented coating decreased. This occurred because the organic component (binder) hardened and shrank as a result of extensive crosslinking formation in the photo-aging process, which corresponds with our previous results using positron annihilation spectroscopy and FTIR (Ishida et al.,
pore generation at the interfacial region between the pigment
by considering the swelling behaviouy combined with the ch
shown in Figure 5, surface topology alteration for the pigmen
this inference. We observed pignent particles exposed at the in surface roughness, which correspond to the

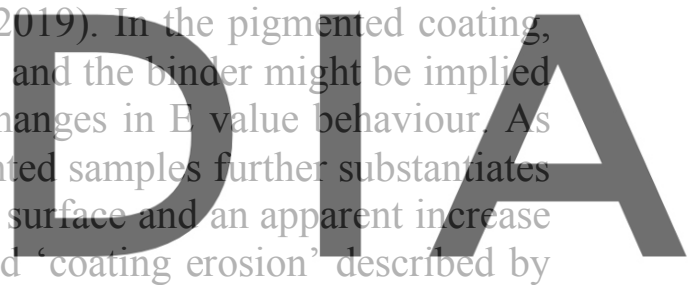
Skaja et al. (2006) and Pang et al. (2014). Figure 6 summarises these intrinsic differences in

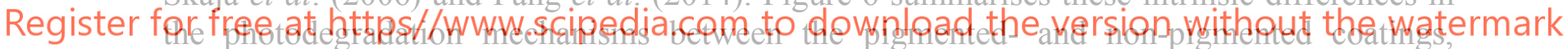
particularly the internal morphological changes. These apparent differences might be attributed to the two following mechanisms.

- Binder selective decomposition around pigments induced by photo-catalytic reaction, i.e. attacking of $\cdot \mathrm{OH}$ radicals generated from $\mathrm{TiO}_{2}$ pigment (Pang et al., 2014).

- Binder shrinkage accompanied by the release of volatile degradation products (Skaja et al., 2006); approximately $10 \%$ shrinkage and $15 \mathrm{wt} \%$ mass loss were observed in the non-pigmented coating in this study after $300 \mathrm{~h}$ of photo-aging.

Neither chalking nor coating erosion occurred on the non-pigmented coatings because these are characteristics of pigmented coatings. Obviously, the interfacial effects occurring at pigment/binder under UV irradiation requires further investigation for better understanding of the photodegradation mechanisms. 


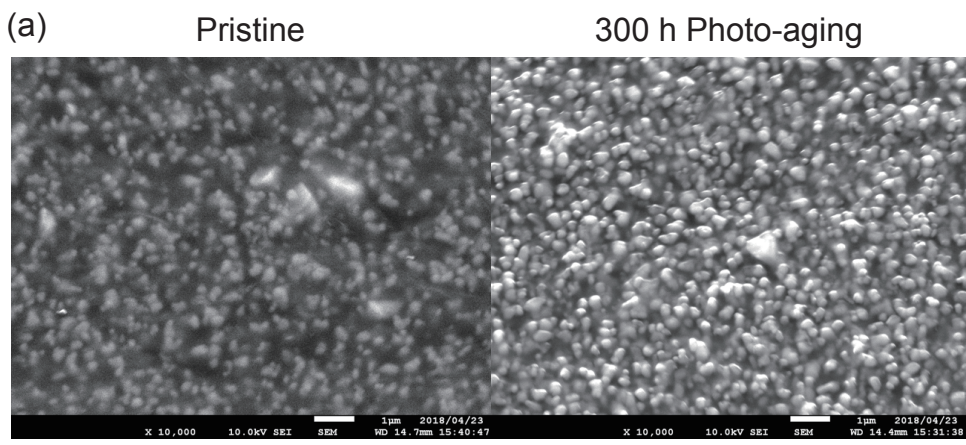

(b)

Pristine

300 h Photo-aging
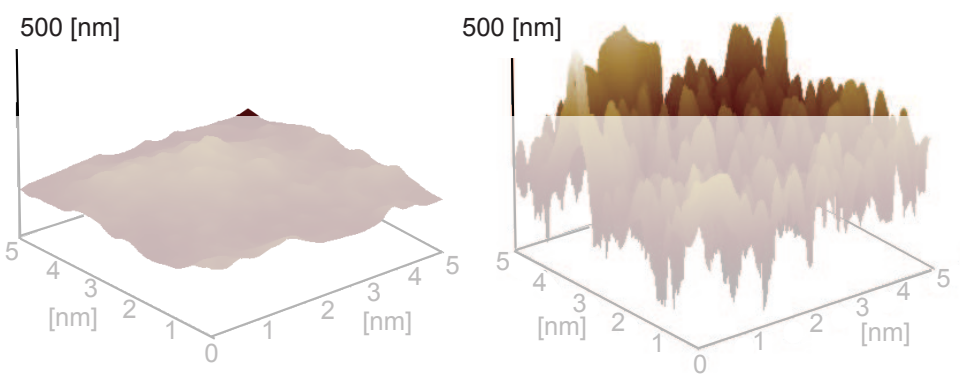

Figure 5. Surface topological changes in pigmented coating before and after photo-aging. (a) SEM images
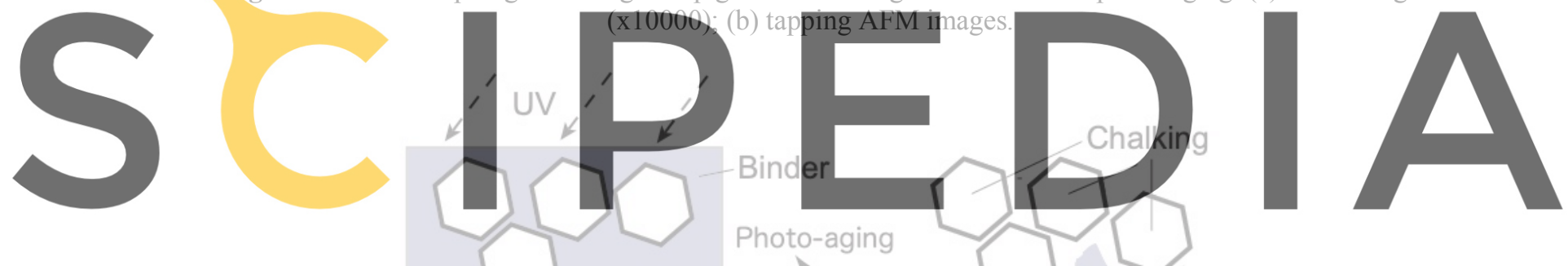

Register for free at https//www.scipedia.com to downlead the version without the watermark

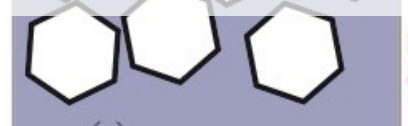

Pore generation @ Interface
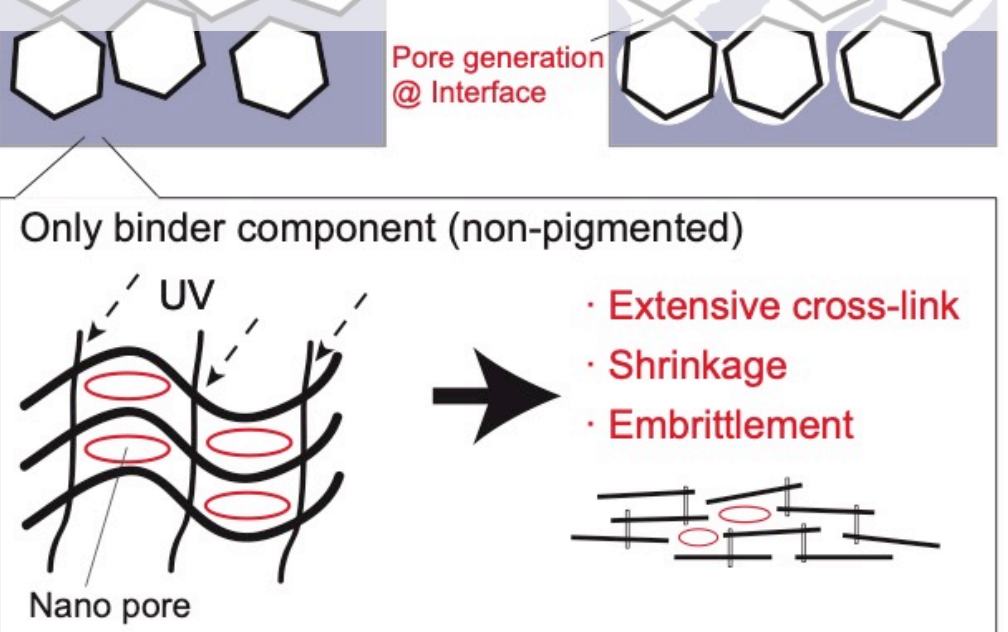

Figure 6. Schematic diagram of the intrinsic differences in the photodegradation mechanisms between pigmented- and non-pigmented coatings in terms of internal morphological changes. 


\section{Conclusions}

Multi-scale analysis of photodegradation was conducted for both pigmented and nonpigmented coatings containing acrylic urethane $+\mathrm{TiO}_{2}$ pigment and only acrylic-urethane, respectively. We discussed the differences in photodegradation between pigmented and nonpigmented coatings and the effect of the interface between the pigment and the binder.

The CI was increased for both coating types in photo-aging, which implies the progression of chemical degradation (oxidation). However, the changes in macroscopic properties did not necessarily correspond with the CI behaviour. Although the E value increased in accordance with the change in the CI, the YI increased for non-pigmented samples and decreased for pigmented samples, showing showed blue shift. It should be noted that although carbonyl species were produced, they were created by differences in the conjugated double bond length. This implies that the photo-catalytic effect of $\mathrm{TiO}_{2}$ pigment might have an influence on the photo-oxidative degradation.

Internal morphological alterations were also studied by analysing the swelling behaviour of samples immersed in toluene. The pore volume of the organic component (binder) was decreased, which might be associated with hardening and shrinkage as the result of extensive cross-linking formation in the aging behaviour of the non-pigmented sample. On the contrary, pore generation at the interfacial region at pigment/binder interface was implied in the pigmented coating. In addition, we observed pigment particles exposed at the surface and an apparent increase in surface roughness. These two features, which are referred to as chalking and coating erosion, effects at the pigment/p processes. Therefore, for better understanding Acknowledgements
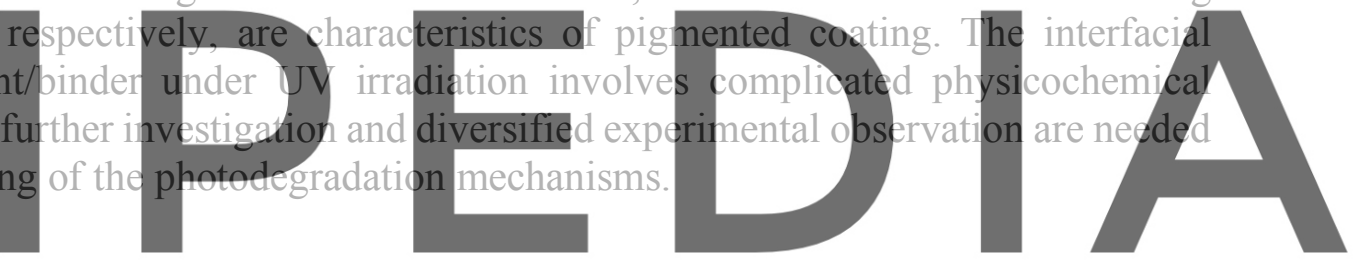

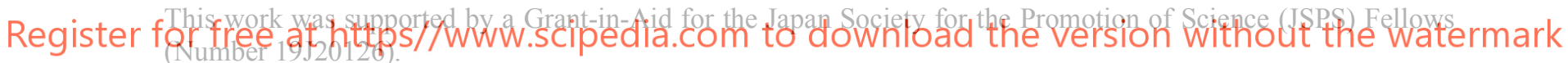

ORCID

Takato Ishida: https://orcid.org/0000-0003-3919-2348

Ryoma Kitagaki: https://orcid.org/0000-0001-6001-3688

Hideaki Hagihara: https://orcid.org/0000-0001-9790-8864

Yogarajah Elakneswaran: https://orcid.org/0000-0001-5496-5551

\section{References}

Bacaloglu, R. and Stewen, U. (2001). Study of PVC Degradation Using a Fast Computer Scanning Procedure. Journal of Vinyl and Additive Technology, 7(3), 149-155. doi: 10.1002/vnl.10283

Courvoisier, E., Bicaba, Y. and Colin, X. (2018). Multi-scale and multi-technical analysis of the thermal degradation of poly(ether imide), Polymer Degradation and Stability, 147, 177-186. doi: 10.1016/J.POLYMDEGRADSTAB.2017

Göbel, L., Bos, C., Schwaiger, A., Flohr, A. and Osburg, A. (2018). Micromechanics-based investigation of the elastic properties of polymer-modified cementitious materials using nanoindentation and semi-analytical modeling, Cement and Concrete Composites, 88, 100-114. doi: 10.1016/j.cemconcomp.2018.01.010

Ishida, T., Kitagaki, R., Yamane, S. and Hagihara, H. (2019). Temperature dependence of structural alteration by ultraviolet irradiation in acrylic-urethane coatings studied by positron annihilation spectroscopy and solvent swelling behavior, Polymer Degradation and Stability, 162, 85-93. doi: 
10.1016/j.polymdegradstab.2019.02.00

Pang, Y., Watson, S.S. and Sung, L.P. (2014). Surface degradation process affected by heterogeneity in nanotitanium dioxide filled acrylic urethane coatings under accelerated UV exposure, Polymer, 55(25), 6594-6603. doi: 10.1016/J.POLYMER.2014.10.030

Richaud, E., Ferreira, P., Audouin, L., Colin, X., Verdu, J. and Monchy-Leroy, C. (2010). Radiochemical ageing of poly (ether ether ketone), European Polymer Journal, 46(4), 731-743. doi: 10.1016/J.EURPOLYMJ.2009.12.026

Rosu, D., Rosu, L. and Cascaval, C.N. (2009). IR-change and yellowing of polyurethane as a result of UV irradiation, Polymer Degradation and Stability, 94(4), 591-596. doi: 10.1016/j.polymdegradstab.2009.01.01

Rouillon, C., Bussiere, P.O., Desnoux, E., Collin, S., Vial, C., Therias, S. and Gardette, J.L. (2016). Is carbonyl index a quantitative probe to monitor polypropylene photodegradation? Polymer Degradation and Stability, 128, 200-208. doi: 10.1016/J.POLYMDEGRADSTAB.2015

Skaja, A., Fernando, D. and Croll, S. (2006). Mechanical property changes and degradation during accelerated weathering of polyester-urethane coatings, Journal of Coatings Technology and Research, 3(1), 41-51. doi: 10.1007/s11998-006-0004-7
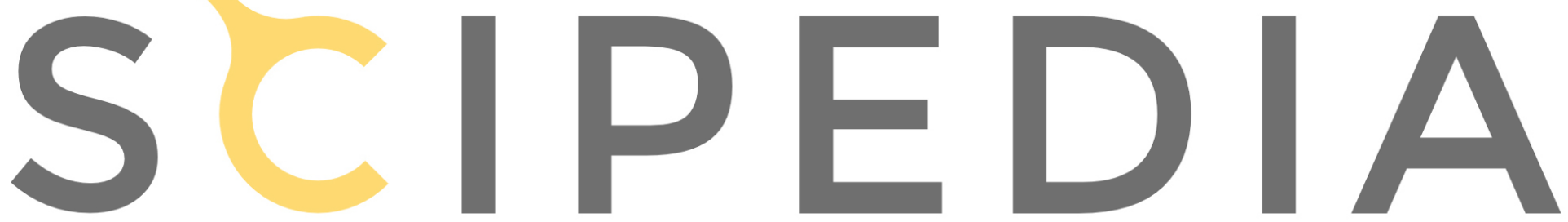

Register for free at https//www.scipedia.com to download the version without the watermark 